\title{
PREVALENCE OF ANXIETY AND DEPRESSION AMONG REHABILITATIONIST(S) WORKING IN PRIMARY AND TERTIARY CARE HOSPITALS
}

\begin{abstract}
\section{BACKGROUND AND AIMS}

The number of studies has documented the increasing anxiety and depression among rehabilitationists due to increased workload, burnout, low pay or self-esteem, etc. However, limited information has found in this regard. Therefore, the study aims to identify the prevalence of anxiety and depression among physical and occupational therapists working in primary or tertiary care hospitals.

\section{METHODOLOGY}

A cross-sectional survey was conducted on physical and occupational therapists at primary and tertiary care hospitals', recruited via convenience sampling technique. The data were collected through the standardized Hospital Anxiety and Depression Scale, sent to participants via email or WhatsApp groups to record responses.
\end{abstract}

\section{RESULTS}

A total number of 147 responses obtained from participants included 121 (82.3\%) females and 26 (17.7\%) males, respectively. It was reported that (52.4\%) participants feel tensed from time to time, (17\%) feel frightened if something about to happen and (32.7\%) have worrying thoughts in their mind a lot of the time. (12.9\%) feel restless very much and $(31.3 \%)$ get sudden feelings of panic quite often demonstrated that majority of therapists 145 (98.6\%) falls into the category of 'anxiety and depression' while only two classified as psychological morbidity.

\section{CONCLUSION}

It was concluded that most therapists have anxiety and depression while few were suffering from psychological morbidity. Moreover, occupational and physiotherapists suffer from bullying during their lives and fail to lead an everyday life suffering from a varying level of distress that may lead to adverse physical and mental consequences. Therefore, multicenter trials should be conducted in the future, considering a large sample size to evaluate the disorder's factors and effective interventions for its management.

\section{KEYWORDS}

Anxiety, Depression, Physiotherapists, Occupational

\section{Ayesha Yousuf}

Lecturer/ Clinical Occupational Therapist

Jinnah Postgraduate Medical Centre aaishyousuf29@gmail.com

[Yousuf A. Prevalence Of Anxiety And Depression Among rehabilitationist(S) Working In Primary And Tertiary Care Hospitals.Pak.j.rehabil.2021;10(1):

DOI: 10.36283/pjr.zu.10.1/012 Therapists, Stress. 


\section{INTRODUCTION}

Depression is a mental disorder characterized by symptoms like lethargy, low self-esteem, and difficulty in feeling asleep, although the leading causes may be related to emotions ${ }^{1}$. The disorder occurs due to the deficiency of positive behavior that manifests as various symptoms such as lack of attention, sleeping, inadequate self-care, and interests in daily life. Similarly, Studies have reported that approximately 4.8 million people all over the world are affected by depression, while half of the individuals also suffer from anxiety. Therefore, depression is considered to be the greatest common cause of disability ${ }^{1}$. According to the World Health Organization (WHO), in Pakistan, $6 \%$ of people get affected with depression, predominantly women are considered to be the main victims of the disorder. Rehabilitationists, including physical and occupational therapists, are a crucial part of healthcare as they tend to promote and restore the wellbeing and health of a patient or client ${ }^{2}$. In addition to it, Physiotherapists works with human movement, pain management, and function, whereas occupational therapist works to improve activities of daily living to make patient independent in their lives. However, due to their nature of work, depression and anxiety seem to be common amongst them ${ }^{3}$. Amid healthcare professionals, depression may lead to sadness, poor performance, and low self-esteem at work. This may lead to having a great impact on the performance, which may ultimately harm (cause a decline in) their productivity and achievement, causing relationship problems such that in maintaining an interpersonal and intrapersonal relationship3. Despite the fact, stress due to occupation in any organization can be a condition due to which employees are not satisfied and unhappy with their respective job environment. Further, a person can be changed and show the feeling of anxiety associated with a behavioral, psychological, and physiological problem ${ }^{4}$. In addition to it, the workload may also be the cause of occupational stress for therapists. Although new emerging therapists feel motivated to work in a new environment often feel mentally exhausted and fatigued due to extensive work hours and its nature. Besides, stress may also be related to working with physicians and managers or administrative staff due to inappropriate instructions or lack of communication between the therapists and supervisors ${ }^{4}$. Moreover, doctors, nurses, psychologists, social workers, physiotherapists tend to react and experience burnout more than other people as they work with sick, unwell people, subsequently gets anxious about their general health. In this context, it was believed that personal attributes and environmental factors must be figured out to evaluate the reason for burnout to reduce the symptoms ${ }^{5}$. On the other hand, a study conducted by Escudero et al. 6 found burnout symptoms in occupational therapists working in concluded that burnout symptoms have a clear risk for the health of occupational therapists that can affects the therapist work environment, affecting the way the treatment strategies are being delivered to the clients. Similarly, Abaoğlu, Demirok, and Kayıhan ${ }^{7}$ demonstrated that the most challenging issue in occupational therapists is burnout-related problems due to depression and stress among health care providers. Moreover, the results indicated that participants who had displayed burnout symptoms were at the risk of burnout should be assessed for their working conditions, level of job satisfaction, and work engagement and emphasis that should be taken into consideration in designing intervention strategies to reduce burnout for occupational therapists ${ }^{7}$. Furthermore, Scanlan and Hazelton ${ }^{8}$ explored the meaningfulness of activities that 
occupational therapists perform in their contextual framework emphasized that higher levels of meaningfulness of work activities were related to higher job satisfaction, a stronger sense of professional identity, and lower burnout. Likewise, Tsai et al. ${ }^{9}$ considered burnout as the most common occurrence in healthcare providers found that burnout in people who are working in the mental health department should be closely noted for the identification of any mental health issue to reduce the amount of stress and burnout.

Despite Qureshi et al. ${ }^{10}$ concluded that there was evidence of mild depression in a few students, but their general health related to mental status was normal due to physical activity. Moreover, a significant relationship was found between physical activity and depression. Furthermore, Paiva, Martins and Paiva ${ }^{11}$ found that in the health care profession, physicians can be the victims of burnout. Still It was also highlighted that burnout is not only the problem for doctors; rather, hospitals should take the responsibility to deals with the burnout and focus on strategies to reduce anxiety and burnout. Hence, self-training, stress management, and communication skills training should be considered to focus on their therapist employees' health and wellbeing, in order to overcome the stress, anxiety and depression among them.

Consequently, Kim et al. ${ }^{4}$ scrutinized the effect of 5 diverse personalities on job stress in physical therapists described the most stressed concerning professional role conflict, work relationship, work overburden, and interpersonal relationship with patient and caregiver. Besides, the job stress of physical therapists is owing to the role of ambiguity. A study conducted by Syed, Syed, and Khan ${ }^{12}$ showed a considerable amount of anxiety and depression found in physical therapy students at the different institutes of Sindh, Pakistan.
Besides, Babur and Maria ${ }^{13}$ depicted that physical therapists with a ratio of $48 \%$ had mild depression, diagnosed with moderate depression were 23.5\%, whereas $29 \%$ had severe depression. On the contrary, $24.9 \%$ had no symptoms of depression. Other factors evaluated were very low financial status and have a salary packages with job dissatisfaction. Due to these factors, the majority of the therapist is suffering from depression.

Several studies have been conducted worldwide to determine the level of anxiety and other mental health-related conditions in different professions. However, there is no research conducted earlier on physical and occupational therapists in Pakistan to evaluate the prevalence of depression and anxiety among rehabilitationists working in primary or tertiary care hospitals. Furthermore, the prevalence will lead to identifying the correlation of psychological distress with certain factors, including the level of satisfaction, nature of work, policies and scarcity of resources in an organization. On the other hand, the reason to conduct this study is to evaluate the prevalence among physical and occupational therapist in both primary and tertiary care about anxiety and psychological stress. It will be a beneficial study in the future as this was never being conducted in Pakistan.

\section{METHODOLOGY}

Study Setting: Data was collected from rehabilitation centers of Karachi, which includes the Institute of Physical Medicine and Rehabilitation (IPM\&R), Liaquat National Hospital (LNH), Jinnah Postgraduate Medical Centre (JPMC) and Dr. Ziauddin Hospital, North and Clifton campuses, respectively.

Target Population: Physical and occupational therapists.

Study Design: Cross-sectional survey.

Duration of Study: 6-8 months. 
Sampling Technique: Non-Probability Convenience Sampling Technique.

Sample size was calculated via using Open EPI software. Therefore, at an anticipated frequency of $50 \%$, Confidence Interval of $95 \%$ with a margin of error at $8 \%$, the sample size of 150 is calculated by using the following formula:

\section{Sample Selection} Inclusion criteria

- Physical and occupational therapists work in primary and tertiary care hospitals, having experience of $>1$ year.

\section{Exclusion criteria}

- Therapists who are unwilling to participate in the study or have less than one year of experience.

Data was collected through Hospital Anxiety and Depression Scale, a reliable tool to assess depression and anxiety in individuals working in an outpatient setting. It has excellent intra-rater reliability and validity. The HADS scale comprised of 14 items and of two subscales that is anxiety and depression, respectively classified as; 0-7 'normal' 810 'borderline' 11 'psychological morbidity' 21 'anxiety and depression' Data Collection Procedure: Data was collected from the rehabilitation department of primary and tertiary care hospitals of Karachi. Moreover, all participants were provided with wellversed consent in order to have detailed information about the study. Followed by the consent, participants were given HADS questionnaire on Google Docs via email or Whatsapp group to evaluate the anxiety and depression among physical and occupational therapists. The questionnaires were distributed to the therapists at a convenient time. The total time required to complete the questionnaires was, on average, 5 -10 minutes. After completing the questionnaire, the record was obtained.
Data was analyzed on Google Docs Editor and SPSS (Statistical Package for Social Sciences) version 20. Furthermore, the demographic characteristics of the participants were represented through frequency, mean and standard deviations, whereas the participant responses were evaluated through frequency and percentage.

Ethical consideration was taken via verbal and written consent by the participant before starting the data collection. All information of the participants was kept anonymous under the investigator's supervision.

\section{RESULTS}

A total number of 147 responses obtained from participants included 121 (82.3\%) females and 26 (17.7\%) males, respectively. The highest number of responses was obtained from the age group of 20 to 25 years (44.9\%) from DPT (46.3\%), BSC-OT (21.8\%), BS-OT (22.4\%) and MS-PT (7.5\%) involved (64.6\%) single and (34.7\%) married participants respectively. The age range included is illustrated in Figure-1.

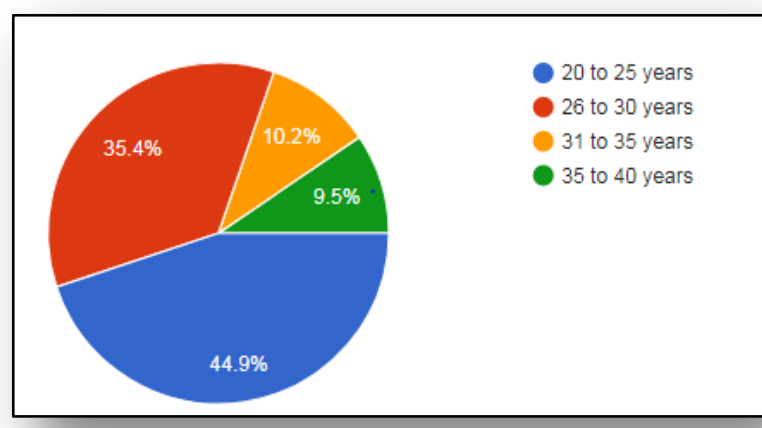

Figure-1 shows the percentage of participant's age group 
On HADS, it was reported that (52.4\%) participants feel tensed from time to time, occasionally while $(22.4 \%)$ feel it most of the time, (17\%) feel frightened if something about to happen and (49\%) felt like slowing down and (12.2\%) have lost interest in appearance whereas (37.4\%) do not take as much care as they should. Moreover, (32.7\%) have worrying thoughts in their mind a lot of the time, as shown in Figure-2.

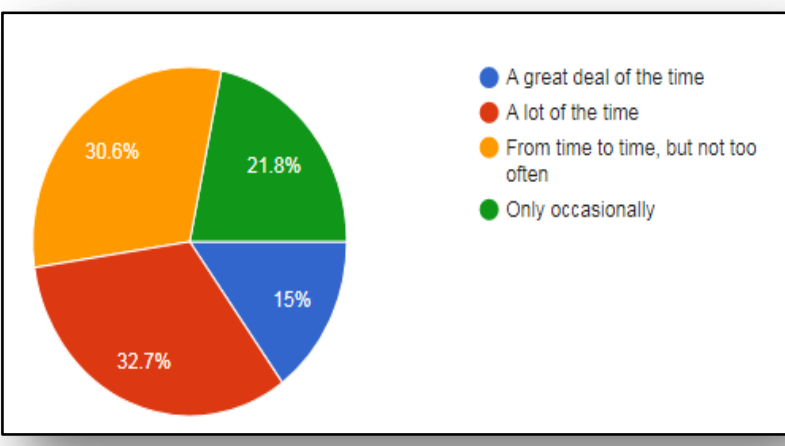

Figure-2 shows the percentage of participant's responses to worrying thoughts

On the other hand, (45.6\%) enjoyed the things they used to but remain $(40.8 \%)$ do not enjoyed quite so much. Furthermore, (56.5\%) can laugh and see the funny side of things as much as they could. Moreover, (55.8\%) feel cheerful sometimes while $(29.9 \%)$ feel it most of the time, $(48.3 \%)$ usually sit at ease or feel relaxed as well as (44.9\%) feels like butterflies in the stomach and (12.9\%) feel restless very much and (24.5\%) quite a lot as shown in the Figure-3.

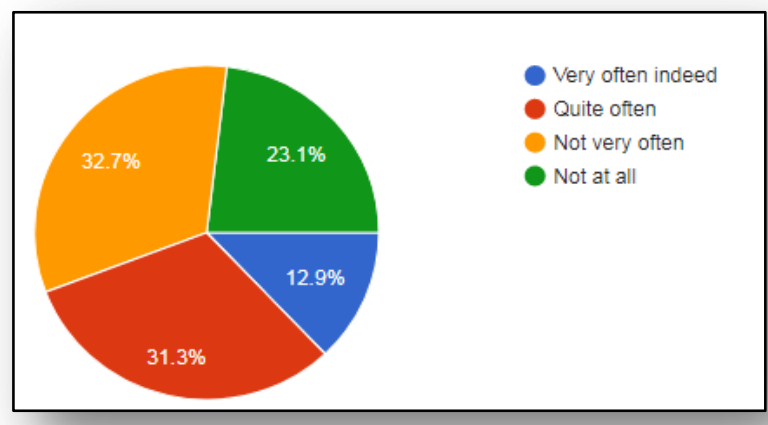

Figure-3 shows the percentage of participant's responses on being restless

On the contrary, (50.3\%) participants looking forward with enjoyment to things as much as they had ever did and (40.1\%) often enjoy a good book, radio or TV program but $(31.3 \%)$ sometimes, get sudden feelings of panic quite often and $(12.9 \%)$ very often as shown in Figure-4.

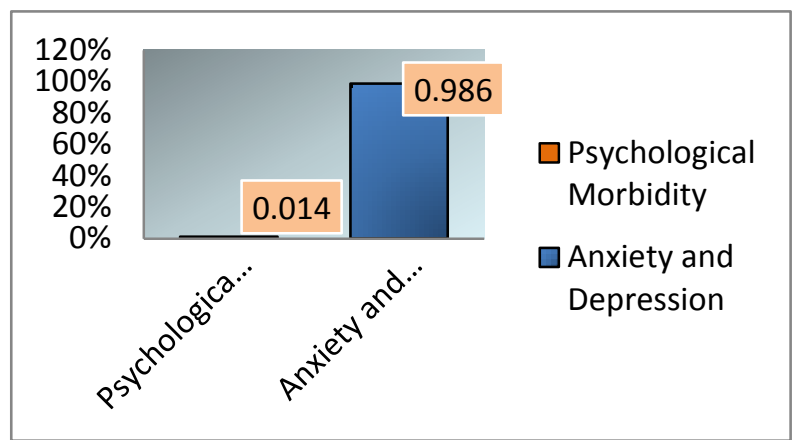

Figure-4 shows the percentage of participant's responses to a panic attack

The total score of HADS demonstrated that the majority of therapists, 145 $(98.6 \%)$, were falls into the category of 'anxiety and depression' while only two classified as psychological morbidity while no individual was found to be in the standard and borderline category among them (Figure-5).

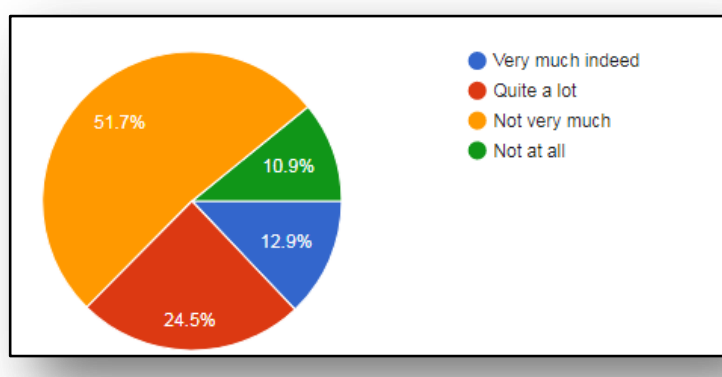

Figure-5 shows total scoring and interpretation on HADS

\section{DISCUSSION}

This study indicated that most therapists have anxiety and depression while few were suffering from psychological morbidity. Yet, It was revealed that most occupational and physiotherapists suffer from bullying during their lives and fail to 
lead an everyday life suffering from a varying level of distress that may lead to adverse physical and mental consequences; similarly, a study conducted in Quetta showed that 35\% of participants had the experience of anxiety and depression that affects their peer and institutional relationship. Moreover, it was also shown that several professionals have adequate knowledge of mental health, while other $65 \%$ have never been subjected to it ${ }^{14}$. Further studies also highlighted that female student suffered more rather than male ${ }^{15,16,17}$. However, in our study, male participants were in a small proportion, so estimation of anxiety and depression cannot be subjected to gender bias. Therefore, several studies must be conducted to investigate the disorders in counterpart gender ${ }^{18}$.

A number of studies revealed that medical residents had been linked to a higher rate of burnout due to depression19. It was further revealed that individuals might face emotional exhaustion and depersonalization due to detachment from the job and inefficacy20. Likewise, in our study, the majority of the participants reported feeling hopeless and lost interest in most of the things. Thus, it has been evident that anxiety and depression may lead to aggression and desertion thoughts at the workplace21.

It has been reported that depression has been accredited with the highest morbidity rate all over the globe and has been a subject of interest to researchers. Therefore, Due to this disorder, therapists often quit their work and search for another work option due to decreased satisfaction and personal achievement in their jobs ${ }^{22}$. Similarly, it was showed that $20 \%$ of residents did not wish to pursue medicine and would even advise others not to choose this field ${ }^{23}$ whereas, due to certain limitation, our study did not investigate alternate job choices of anxiety ${ }^{24}$. Further, it was also observed that therapists felt depressed after the occurrence of incidence ${ }^{25}$.

The results also highlighted the emotional vulnerability of a significant proportion of therapists. Academic and personal issues being the most significant concern such as stressful events and mood are more difficult to control; manipulation of curricular factors may have positive effects on academic sources of stress. However, In the modern era, depression has become a crucial subject that has affected many but only reported by some due to lack of awareness, fear of rejection, or achievement in one's career. Moreover, students who had unhealthy diets or smoking habits had significantly higher levels of psychiatric symptomatology ${ }^{26}$. Therefore, future studies should intervene with some suggestions for dealing with stressful aspects of professional education. Besides, there is an imperative need to establish the prevention programs and bring out evidence-based psychological healthcare promotions for the physiotherapy and occupational therapy students in Pakistan to create smooth adjustments between different learning environments with changing learning needs and a growing academic burden. However, promoting new ways of learning among the physiotherapy and occupational therapy students will help them in their mental, social and physical growth and developed coping skills for future task.

This study is significant to highlight the prevalence of psychological morbidity and anxiety-depression among rehabilitationists working in primary and tertiary care settings using a standardized questionnaire.

However, due to certain limitations in our questionnaire, some questions were not incorporated, and relatively of, a small sample size causes limitation to analyze factors of anxious behavior and its 
magnitude in the targeted population. Therefore, large-scale surveys should be conducted to analyze the burden of depression to lead to counsellors or psychiatrists' need to address this issue as the majority of individuals fail to talk about it.

\section{CONCLUSION}

It was concluded that the most of therapists have anxiety and depression while few were suffering from psychological morbidity. Moreover, occupational and physiotherapists suffer from bullying during their lives and fail to lead an everyday life suffering from a varying level of distress that may lead to adverse effects which includes physical and mental consequences. Due to which it becomes difficulty for them to cop up with their activities of daily living. Therefore, multicentre trials should be conducted in the future, considering a large sample size to evaluate the factors related to the disorder and effective interventions for its management.

\section{REFERENCES}

[1] Gul F, Yuefen W, Ullah I, Zada S. Study of depression in university students in Pakistan. JPMA. The Journal of the Pakistan Medical Association. 2020 Apr 1;70(4):650-4.

[2] Carvalho MN, Gil CR, Costa EM, Sakai $\mathrm{MH}$, Leite SN. Needs and dynamics of the Primary Healthcare workforce in Brazil. Ciência \& Saúde Coletiva. 2018;23:295-302.

[3] Lork K, Holmgren K, Danielsson L. A short work-directed rehabilitation to promote work capacity while depressed and anxious: a qualitative study of workers' experiences. Disability and Rehabilitation. 2019 Dec 24:1-0.

[4] Kim EH, Jang HY, Lee SM. The effect of 5 different personalities on job stress in physical therapists. Physical
Therapy Rehabilitation Science. 2018 Dec 28;7(4):191-6.

[5] Śliwiński Z, Starczyńska M, Kotela I, Kowalski T, Kryś-Noszczyk K, LietzKijak D, Kijak E, Makara-Studzińska M. Burnout among physiotherapists and length of service. International journal of occupational medicine and environmental health. 2014 Apr 1;27(2):224-35.

[6] Ayala-Escudero A, Hernández-Rincón EH, Avella-Pérez LP, Del Mar MorenoGómez M. Family physician's role in the primary and secondary prevention and in the treatment of depression in the elderly. Semergen. 2020 Dec 2.

[7] Abaoğlu H, Demirok T, Kayıhan H. Burnout and its relationship with work-related factors among occupational therapists working in public sector in Turkey. Scandinavian Journal of Occupational Therapy. 2020 Mar 23:1-0.

[8] Scanlan JN, Hazelton T. Relationships between job satisfaction, burnout, professional identity and meaningfulness of work activities for occupational therapists working in mental health. Australian Occupational Therapy Journal. 2019 Oct;66(5):581-90.

[9] Tsai J, Jones N, Klee A, Deegan D. Job Burnout Among Mental Health Staff at a Veterans Affairs Psychosocial Rehabilitation Center. Community Mental Health Journal. 2020 Feb 1;56(2):294-7.

[10] Qureshi S, Riaz H, Awan MM, Khushnood K, Hussain R. Association of depression, physical activity levels and general psychological health among physical therapy students of Rawalpindi and Islamabad. Journal of Shifa Tameer-e-Millat University. 2019 Jul 21;2(1):26-30.

[11] Paiva CE, Martins BP, Paiva BS. Doctor, are you healthy? A cross-sectional investigation of oncologist burnout, depression, and anxiety and an investigation of their associated 
factors. BMC cancer. 2018 Dec 1;18(1):1044.

[12] Syed A, Ali SS, Khan M. Frequency of depression, anxiety and stress among the undergraduate physiotherapy students. Pakistan journal of medical sciences. 2018 Mar;34(2):468.

[13] Babur MN, Liaqat M. Prevalence and factors effecting depression, stress and anxiety among physiotherapists of Pakistan. Isra Med J. 2017;9(6):42730.

[14] Michopoulos I, Furukawa TA, Noma $H$, Kishimoto $S$, Onishi A, Ostinelli EG, Ciharova M, Miguel C, Karyotaki E, Cuijpers P. Different control conditions can produce different effect estimates in psychotherapy trials for depression. Journal of Clinical Epidemiology. 2020 Dec 15.

[15] Zsila Á, Orosz G, McCutcheon LE, Demetrovics Z. A lethal imitation game? Exploring links among psychoactive substance use, selfharming behaviors and celebrity worship. Addictive Behaviors Reports. 2020 Dec 1;12:100319.

[16] Ahmer S, Yousafzai AW, Siddiqi M, Faruqui $R$, Khan R, Zuberi S. Bullying of trainee psychiatrists in Pakistan: a cross-sectional questionnaire survey. Academic Psychiatry. 2009 Jul 1;33(4):335-9.

[17] Frank E, Carrera JS, Stratton T, Bickel J, Nora LM. Experiences of belittlement and harassment and their correlates among medical students in the United States: longitudinal survey. bmj. 2006 Sep 28;333(7570):682.

[18] da Silva JL, de Oliveira WA, Komatsu $A V$, Zequinão MA, Pereira BO, Caravita SC, Skrzypiec G, Silva MA. Associations Between Bullying and Depression Among Students in School Transition. Trends in Psychology. 2020 Mar 16:13.

[19] D'Oliveira TC, Anagnostopoulos A. The Association Between Shift Work And Affective Disorders: A Systematic
Review. Chronobiology International. 2020 Nov 23:1-9.

[20] Alkhamees AA, Alaqil NS, Alsoghayer AS, Alharbi BA. Prevalence and determinants of burnout syndrome and depression among medical students at Qassim University, Saudi Arabia. Saudi Medical Journal. 2020 Dec 1;41(12):1375-81.

[21] Schwickerath J, Zapf D. Inpatient Psychotherapy of Bullying Victims. Bullying and Harassment in the Workplace: Theory, Research and Practice. 2020 Apr 9.

[22] Cooper KM, Gin LE, Barnes ME, Brownell SE. An exploratory study of students with depression in undergraduate research experiences. CBE-Life Sciences Education. 2020;19(2):ar19.

[23] Lai R, Plakiotis C. Stress and wellbeing of psychiatry trainees: a literature review. GeNeDis 2018. 2020:117-26.

[24] Farley A, Kennedy-Behr A, Brown T. An Investigation Into the Relationship Between Playfulness and Well-being in Australian Adults: An Exploratory Study. OTJR: Occupation, Participation and Health. 2020 Jul 29:1539449220945311.

[25] Crowe $M$, Inder $M$, Porter $R$, Wells $H$, Jordan J, Lacey C, Eggleston K, Douglas K. Patients' Perceptions of Functional Improvement in Psychotherapy for Mood Disorders. American Journal of Psychotherapy. 2020 Dec 11:appipsychotherapy.

[26] Brytek-Matera A, Onieva-Zafra MD, Parra-Fernández ML, Staniszewska A, Modrzejewska J, Fernández-Martínez E. Evaluation of Orthorexia Nervosa and Symptomatology Associated with Eating Disorders among European University Students: A Multicentre Cross-Sectional Study. Nutrients. 2020 Dec;12(12):3716. 